\title{
G9 - Implementation of a Cells Database System - An efficient validated tool for management of biological materials
}

Milena Mouta Verdan França Carvalho ${ }^{1 *}$; Rodolpho Silva de Paula ${ }^{2}$; Fernanda Mota Borges²; André Queiroz da Silveira²; Renato Ferreira Dib³; Márcia Arissawa ${ }^{1}$.

1 - Laboratório de Tecnologia de Anticorpos Monoclonais / ViceDiretoria de Desenvolvimento - Bio-Manguinhos / FIOCRUZ;

2 - Seção de Desenvolvimento de Sistemas / Divisão de Tecnologia da Informação - Bio-Manguinhos / FIOCRUZ;

3 - Laboratório de Metrologia e Validação/BioManguinhos/FIOCRUZ.

\section{Introduction:}

Detailed information related to a biological materials bank constitutes the main source of information about the laboratory activities and development over the time. Throughout its existence, the Monoclonal Antibodies Laboratory developed more than five hundred clones, totaling more than five thousand cells currently stored. Based on this fact and in the search for innovation and continuous improvement of internal processes, it has become imperative to develop a tool that could provide access to information quickly, ensuring the storage and traceability of the samples in a consistent and secure manner. In this work, the system development and implementation was based on cell storage, but can also be applied to other biological materials. In addition, this tool was validated according to the current regulatory requirements in order to avoid nonconformities in audit processes.

\section{Objective:}

System validation and implementation for the management of biological materials, according to the requirements of Good Manufacturing Practices.

\section{Methodology:}

This system was developed using requirements engineering with prototyping in a network environment, allowing multi-user access on web server. The validations steps were done in accordance with ANVISA RDC 17, consisting on risk analysis, installation qualification, operational qualification and performance qualification. Features and specifications were previously established. 


\section{Results:}

All cell data contained in our archives was manually inserted in system, with a total of 1.217 frozen lots and 5.562 cryogenic vials stored. The system supported all the details of the processes that gave rise to every cell and the characterization of the antibodies expressed by each strain. Moreover, the organization of the deposits in matrix form, makes it easier to find the biological materials location. In addition, the system provides a range of reports, with moves and consumption data, quantitative volumes obtained, supporting the recovery of information.

\section{Conclusion:}

Based on the validation process, the system leads to the expected results, providing traceability and reliability in information storage, being prepared to suit the storage of other biological materials, in addition to cells. It represents a valuable time consumption reduction and reliability of storage information that will certainly assist laboratories that need to meet regulatory requirements.

Keywords: Cell bank, management system, validation, traceability, security 